\title{
El léxico deportivo de las crónicas periodísticas del Mundial de fútbol 2010 ganado por España en El Poema de Mío Cid 1
}

\author{
Isidoro ARROYO AlMARAZ \\ Universidad Rey Juan Carlos \\ isidoro.arroyo@urjc.es \\ Francisco GARCÍA GARCÍA \\ Universidad Complutense de Madrid \\ fghenche@gmail.com
}

Recibido: 21 de marzo de 2012.

Aceptado: 10 de mayo de 2012 .

\begin{abstract}
Resumen
El enfoque de esta investigación es el estudio comparado del léxico del lenguaje épico de las crónicas deportivas de fútbol escritas con el léxico del lenguaje épico de El Poema de Mío Cid, para rastrear la presencia de los léxicos épicos de las crónicas deportivas actuales en El Poema de Mío Cid. Comparamos el léxico bélico, jurídico, lúdico, mágico y social de diez crónicas deportivas del Campeonato del Mundo de Fútbol de 2010, con la presencia de ese mismo léxico en El Poema de Mío Cid. Se concluye que El Poema de Mío Cid está presente en las crónicas deportivas de la derrota y de la victoria de España en el Campeonato Mundial de Fútbol de 2010.
\end{abstract}

Palabras clave: Crónicas deportivas escritas; El Poema de Mío Cid; Léxico; Campeonato Mundial de Fútbol; Lenguaje épico.

\section{The lexicon sport of journalistic chronicles during the 2010 Football World Cup won by Spain in the Poem of the Cid}

\begin{abstract}
The research focus on is the comparative study of the lexicon of the language of the chronicles epic sport of football reports written with the lexicon of the language epic in The Poem of the Cid, in order to track the presence of lexical epic chronicles current sports in The Poem of the Cid. We compare the vocabulary of war, legal, playful, social and magical ten sport reports of the Football World Championship 2010, with the presence of the same vocabulary in The Poem of the Cid. We conclude that The Poem of the Cid is present in the defeat and the victory sport chronicles of Spain in the World Cup 2010.
\end{abstract}

Key words: Written sport reports; Poem of the Cid; Lexicon; Football World Cup; Epic language.

\section{Referencia normalizada}

Arroyo Almaraz, I., García García, F. (2012). El léxico deportivo de las crónicas periodísticas del Mundial de fútbol 2010 ganado por España en El Poema de Mio Cid. Historia y Comunicación Social, Vol. 17, páginas 317-341.

Sumario: 1. Introducción. 2. Estado de la cuestión. 3. Metodología. 4. Análisis de los Datos. 5. Conclusiones. 6. Bibliografía. 


\section{Introducción}

La sección de deportes de la prensa escrita ha sido objeto de estudio a lo largo de las últimas décadas por su interés literario debido al uso de un lenguaje particular. El fútbol, de todos los deportes, ha sido el que más interés ha despertado por su singularidad, configurando en sí mismo una lengua especial del periodismo, el lenguaje del fútbol que, a pesar de presentar características léxicas propias de la lengua común (Santamaría, 1995) se ha caracterizado por un uso extensivo de extranjerismos, metáforas, polisemias, siglas, acrónimos, eponímias, locuciones verbales, adverbiales, adjetivales o nominales (Medina, 2011; Marín, 2000, Castañón, 1993; Aleixandre (et al.), 2007; Mapelli, 2004) para:

embellecer las crónicas con expresiones nuevas y creativas que, a través de los medios de comunicación, entran a formar parte de la tradición, de la «cultura» futbolística. Así pues, el lenguaje deportivo ha creado una fraseología propia, un amplio caudal de expresiones que se han generalizado y fijado; los periodistas, al lado de las intuiciones individuales que pueden ser de carácter efímero y de uso restringido, recurren a estas unidades léxicas (Mapelli, 2004: 171).

Las crónicas deportivas de fútbol poseen por su propia definición la narración de acciones de oposición definidas bajo un concepto bélico de forma "continuada narrados por sus propios protagonistas o testigos de los mismos, con un orden temporal" (Vivaldi, 1981: 123) ${ }^{2}$, un origen histórico y literario que las emparenta con los relatos épico-líricos de la antiguëdad y muy particularmente con los cantares de gesta y los romances (Labrador, 2007; Tamayo y Esquivel, 2005; Gallego, 1959; Hernández, 1999).

Nos hemos fijado en El Poema de Mío Cid (1140), por tratarse de una cumbre de la literatura española y universal, por ser el cantar de gesta en el que aparecen, por primera vez, las voces "deportar y deportarse" (Hernández, 1999: 2):

Los que ian mesurando e llegando delant

Luego tan armas e tománse a deportar

Por çerca de Saalón tan grandes gozos van

(Poema de Mío Cid, versos 1513-1515)

sinon amas sus mugieres doña Elvira e doña Sol:

deportarse quieren con ellas a todo su sabor

(Ibid., versos 2710-2711)

La voz deportar se refiere a deportarse que, según el Diccionario de Autoridades de R.A.E. (1990: 75), tiene el significado de "Divertirse, espaciarse, solazarse. Tiene poco uso, y viene del nombre Deporte". Etimológicamente deporte significa "Diversión, holgúra, pasatiempo". Es compuesto de la preposición De, y la voz Porte:

y como esta signifique el trabajo de portear o pasar las cosas de unos paráges á 
otros, puede ser se dixesse Deporte para explicar se deponía absolutamente todo lo que era cuidado y fatiga para divertirse mejor (Diccionario de Autoridades, 1990:75)

Por todo ello hemos fijado el objeto de interés en el estudio comparado del léxico del lenguaje épico de las crónicas deportivas de fútbol con el léxico del lenguaje épico de El Poema de Mío Cid, para rastrear la presencia de los léxicos épicos de las crónicas deportivas actuales en El Poema.

La palabra épica, etimológicamente procede del "epos" griego que significa palabra, por tanto "epea", su plural significa palabras, es decir relato. Tanto la épica clásica como la medieval, donde se incluye El Poema de Mío Cid, cuentan y relatan gestas, acciones encarnadas en sus héroes que son los que vencen los obstáculos para ganar. Por tanto, si son acciones, implican movimiento, lo mismo que acontece en el relato de las crónicas deportivas de fútbol.

Igual que la épica clásica podía ser oral o escrita, las crónicas deportivas pueden ser enunciadas oralmente a través de la radio, por escrito a través de la prensa escrita o representada icónicamanente a través de las retransmisiones televisivas. Esta investigación se centra en en el análisis de las crónicas derportivas de fútbol escritas.

Nos interesa comprobar cómo los léxicos de las crónicas deportivas de fútbol están presentes en El Poema de Mio Cid. Comparamos el léxico bélico, jurídico, lúdico, mágico y social de diez crónicas deportivas del Campeonato del Mundo de Fútbol de 2010, con la presencia de ese mismo léxico en El Poema de Mío Cid.

Nos hemos centrado en las crónicas de la derrota de España en el partido contra Suiza y de la victoria de España en el partido contra Holanda con la que obtuvo el Campeonato del Mundo del 2010, porque representan los dos extremos del acontecimiento más trascendente del fútbol español, si no habría que remontarse a 2012, 2008 o a 1964 cuando España ganó la Copa de Europa de Naciones.

Los datos de tratamiento y éxito de audiencia, tanto en prensa como en radio, televisión e Internet hablan por sí solos; tal y como señala Herrero (2011: 162):

el periódico Marca de 12 de julio de 2010, día post-victoria, 58 de las 66 páginas de ese número estuvieron dedicadas integramente al triunfo de la Selección (...) El diario As dedicó 51 páginas; Sport 28 páginas y Mundo Deportivo 38 páginas.(...) El partido fue seguido (en television) por una media de casi 14 millones de personas y la prórroga por una media ( de más) de 15 millones.

Por otra parte, ambos partidos, son dos relatos épicos sobresalientes que con claridad ponen en juego las mejores virtudes y vicios de los héroes y villanos en el contexto simbólico de la contienda entre naciones.

Las crónicas deportivas reproducen, cuando se trata del enfrentamiento entre dos selecciones nacionales o dos grandes equipos, el mismo esquema que preside los cantos épicos de la Iliada, La Odisea, La Chanson de Roland, o El Poema del Mío Cid. Siempre hay un enemigo a batir que representa el mal y un héroe que encarna todas las virtudes (Aleixandre-Benavent (et al.), 2007: 118). 
Además, como bien señala Labrador (2007: 28), en los torneos internacionales se acentúan más los aspectos bipolares del combate y la narración épica se presenta como un verdadero enfrentamiento entre nosotros y ellos, donde el periodista se compromete y toma partido claramente a favor de los propios. Utiliza un lenguaje sencillo, repleto de terminología propia a base de apuntes técnicos, anécdotas, recursos literarios, etc. haciendo más atractivo el mensaje al lector.

El lenguaje deportivo de la victoria de España en el Mundial 2010 ya ha sido objeto de estudio por otras investigaciones que han atendido a diversos aspectos formales de contenido: textual, visual, etc. Y de la trascendencia mediática a través de portadas y contenidos de periódicos, influencia del evento en la política, trascendencia a través de la prensa rosa, creación de un mito, venta de producto de merchandising o creación de imagen de marca con mensajes publicitarios de apoyo a la Selección (Herrero, 2011).

Nosotros nos proponemos abordarlo desde un análisis del léxico donde, además del léxico bélico, estudiado, entre otros, por Barrero (2011), Alcoba (1981) y Herráez (2004), estudiaremos los léxicos jurídicos, mágicos, lúdicos y sociales del contenido de las crónicas deportivas de los diarios de mayor impacto del día siguiente de los partidos de fútbol, para posteriormente compararlo con los léxicos equivalentes en El Poema de Mío Cid, con la certeza de que conocer los discursos épicos del pasado nos sirve para entender y justificar las crónicas deportivas del presente y abrir una nueva vía de conocimiento del lenguaje periodístico deportivo.

\section{Estado de la cuestión}

La relación entre crónica y El Poema de Mío Cid se deben inicialmente a las aportaciones de Menéndez Pidal, cuando en 1898 publicara su célebre estudio El Poema del Cid y las Crónicas generales de España donde, como bien dijera Pedro Salinas (1976: 83):

Menéndez Pidal ha mostrado que nuestra tradición más antigua es la épica. Nuestros primeros poetas no interpretan, ni preguntan, ni idealizan: se limitan simplemente a contar. Cuentan las realidades históricas más cercanas a ellos. Como en el caso de gran parte de la literatura medieval, el tema surge de las hazañas históricas (...) La primera actitud del poeta español ante la realidad histórica se manifiesta en el poema épico narrativo. La realidad en la España medieval se cifra en proezas y hazañas; de ahí su designación poética, "cantar de gesta".

Las investigaciones recorren la historia de la literatura española con trabajos posteriores como los de Catalán (1963), Dyers (1980) o De Bustos Tovar (1992) y llegan al periodismo con investigaciones como la que presentamos. Así, en la literatura, muy tempranamente se inciaron los Romances, una suerte de crónica que recoge tanto los acontecimientos como su interpretación, eran poemas épico-líricos. Nos lo encontramos en los Romances del Rey Rodrigo, en Bernardo del Carpio, en Historia de los Siete Infantes de Lara, en Romances del Cid, y en Romances 
Fronterizos y Moriscos. La proporción entre los hechos épicos narrados y la expresividad lírica es muy diferente de unos textos a otros. Posteriormente la literatura ha mantenido viva esta tradición entre épica-lírica y crónica a través, en otros géneros, de la novela futbolística, del cuento o de la oda.

El periodismo hereda esta tradición épico-lírica y la incorpora a la crónica deportiva, al tiempo que, al hacer las crónicas del presente, remite a formas utilizadas en la poesía épica del pasado. A su vez, los poetas utilizan temas, contenidos y formas de decir de las crónicas deportivas del fútbol para construir, de una manera más poderosa, la figura del héroe moderno. Así se refleja en la Oda escrita por Rafael Alberti al guardameta del F.C. Barcelona Platko, cuando el guardamenta fue lesionado el 20 de mayo de 1928 en la final del campeonato de fútbol de España entre la Real Sociedad de San Sebastián y el F.C. Barcelona. Los cronistas del partido de fútbol de los diarios $\mathrm{ABC}$ y $\mathrm{El} \mathrm{Sol}$, tal y como señala el estudioso de la literatura española, catedrático y crítico literario Antonio Gallego Morell en el diario ABC $(22 / 02 / 1959)$, describieron la lesión del guardameta y construyeron un personaje con metáforas y expresiones utilizadas por la poesía. Así, por ejemplo, cuando Rafael Alberti escribe en su Oda a Platko, recogido en su libro Cal y Canto, "ni el mar,/que frente a ti saltaba sin poder defenderte,/ ni la lluvia. Ni el viento, que era el que más regía", el cronista de $\mathrm{ABC}$ lo relata: "El fuerte viento, constante que recogerá de través el juego (...) influye en el juego del fuerte viento".

Nuestro objetivo consiste en establecer relaciones entre el léxico de las crónicas deportivas de fútbol y el léxico coincidente en El Poema de Mío Cid, estableciendo cinco tipos de léxicos:

El léxico bélico basado en la relación entre la lucha armada y la lucha deportiva, entre los combates de El Poema de Mío Cid y el primer partido con derrota de España y el último con victoria, conquistando el Campeonato del Mundo de Fútbol, referidos en las crónicas deportivas. En ambos casos se impone al cronista la fuerza del léxico (White, 2001; Elias 1994; Barthes, 1957). Como bien dice Herráez (2004: 117): "La analogía global entre la lucha armada y la lucha deportiva se impone de manera demasiado evidente para que el cronista pueda escapar a ella y encontrar en otra parte vocablos más aptos". Se podría decir lo mismo respecto a la crónica deportiva y la crónica histórica de los cantares de gesta:

El deporte como la guerra, está construido sobre el concepto de oposición. Ambos comparten el aspecto agonístico de lucha y sufrimiento. En el deporte, esta lucha está perfectamente reglamentada y ritualizada, como choque de dos fuerzas activas: ataque contra defensa; buena suerte, mala suerte; instinto, estrategia; valor físico y valor moral (Ibid.)

Esta oposición se percibe claramente en nuestro estudio ya que para ganar hay que luchar y en la lucha se gana y se pierde. España contra Suiza, pérdida, desilusión, mala suerte, angustia; España contra Holanda, la tensión de la victoria, la memoria, la construcción de una historia para siempre, ganar, vencer, vivir, recordar. También en El Poema de Mío Cid se impone un duelo entre las partes, una lucha, una derrota, una victoria, una heroicidad para siempre, memoria histórica de la identidad 
de España. El Cid gana batallas hasta después de muerto.

El léxico jurídico basado en la relación de los derechos y los deberes de una forma ritualizada del combate, del partido de fútbol, cuándo y dónde terminan las batallas, cuál es el respeto que se deben vencedores y vencidos, quién dirige, arbitra, sanciona y reparte justicia en cada partido, cuáles son los límites y las posibilidades del juego, hasta dónde llega la norma y hasta dónde se limita la creatividad a través de las reglas que impone el juego sin las cuales no hay juego, no hay guerra, no hay derrota, no hay victoria.

La violencia existente en el fútbol debe ser regulada, como dice Labrador (2007: 46):

Este agonismo fundante se actualiza en cada representación -en cada juego, en cada partido- permitiendo el ritual y consumándolo (...) Es necesario un discurso, un dispositivo de razón, para dominar la violencia, las pulsiones desestructuradas en el seno de una comunidad.

Y esa razón debe apoyarse en una razón jurídica construida a través de las reglas del juego.

El léxico lúdico basado en la relación simbólica entre ganadores y perdedores dentro de un juego que es el fútbol. El léxico propio de los juegos constituye un rico componente para establecer las relaciones simbólicas de los contendientes. Está presente el campo de representación, el sistema arbitrado de puntos, los goles, que llegan a significar la victoria o la derrota.

La semiótica de los torneos actualiza su vocabulario en una nueva semiótica del espectáculo deportivo:

Banderas, cancerberos, rivales, puntas de lanza, defensas, estrategias, uniformes, trofeos, tesoros (copas), castigo, descanso, en ocasiones de territorios lejanos, que compiten y obtienen su máximo galardón cuando penetran la portería de la escuadra contraria, en clara alusión a la simbología medieval de los torneos (Arroyo y García, 2002: pp. 188-189).

Así por ejemplo se puede comparar El Romance del Rey Don Rodrigo cómo perdió a España con la crónica deportiva de una derrota importante de la selección española de fútbol, o bien de cualquier equipo en una final de trofeos continentales. (Arroyo y García, 2002a: 30)

Romance Del Rey Don Rodrigo cómo fugó de la batalla ${ }^{3}$ Ya se sale de la priesa el rey Rodrigo cansado pusiérase hacia una parte por de alli mirar su campo; ve que su gente se apoca, y cómo va desmayando. Desque esto vido Rodrigo, no curó de más mirallo, porque bien ve que los suyos ya no pueden soportallo. Volvió las riendas apriesa, da de espuelas al caballo; huyendo va a más andar por un tremedal abajo.

Si comparamos este Romance con el léxico analizado en las diez crónicas obser- 
varemos que palabras como batalla, cansado, gente, campo, etc. aparecen indistintamente en el Romance y en las Crónicas Deportivas.

El léxico mágico basado en lo mágico y/o religioso muestra la idea de trascedencia de la implicación de lo divino, de la fuerza del destino, el valor de la hazaña, de la liturgia del espectáulo en la historia. "El virtuosismo muscular, tribal, nacionalista se enmarca en espectáculos litúrgicos gigantescos, magnificados por el magma televisivo" (Giner, 2003: pp.142-143).

La intervención de lo divino en la historia humana, inscribiéndola en una dimensión de trascendencia, de destino colectivo, podría funcionar de modos comparables en ambos discursos. Las invocaciones a la divinidad o las alusiones a las prácticas religiosas han llegado a ser tópicas en el discurso deportivo (Labrador, 2007: 36).

En la épica clásica y medieval, los héroes son semidioses; en la épica clásica, porque están vinculados familiarmente a los dioses, y en la épica medieval, como El Cid, porque hay siempre una fuerte vinculación con Dios, con la Iglesia y con los ideales de una sociedad basada en la lucha contra el infiel.

En las crónicas deportivas de fútbol los deportistas son héroes relacionados con lo divino. Los ejemplos son múltiples La mano de Dios, mano de Maradona que, inflingiendo la norma, lleva a la selección Argentina a la consecuención del triunfo final frente a Inglaterra en el Campeona Mundial de Fútbol, celebrado en México. El Santo de Casillas o el Mesías de Leo Messi.

Lenguaje social basado entre los actores del espectáculo deportivo futbolístico en el que intervienen los jugadores, árbitros, entrenadores, presidentes de clubes y muy especialmente el público que activa sus interrelaciones sociales entre sí y en relación al espectáculo que se está produciendo en el campo de juego. Nacen así las referencias a las identidades. Lo importante de un equipo es la dimensión simbólica identitaria en relación al espacio y el tiempo, en relación a los objetivos sociales que se propone el equipo, ofrece la victoria y la derrota y con ello forma parte de una identidad social de la ciudad o del ámbito socio-cultural en que se inserta. Por tanto no sólo se juega al fútbol, sino que jugando al fútbol se satisface una demanda social que va más allá del puro espectáculo deportivo. En definitiva "El fútbol es una actividad dotada de un tremendo potencial de creación de sentido por medio del cual proporciona a los individuos esquemas y herramientas con los que dominar las relaciones sociales y el tiempo" (Llopis, 2006: 124). Lisbona, Medina y Sánchez (2006: 1), mencionando a Norbert Elias, indican cómo la actividad físico deportiva es una actividad social, total, capaz de reflejar las problemáticas y los valores sociales del momento histórico en el cuál se embarca.

Las crónicas, tanto deportivas como históricas, tienen dos grandes componentes; por una parte, la información $\mathrm{y}$, por otra, la interpretación desde una perspectiva lírica. Francisco López Estrada (2007: 9) en el prólogo a El Poema del Mío Cid, refiriéndose al comienzo del Poema cita dos palabras. "poema y poesía que indican las piezas que logran el carácter de poéticas en sus diferentes acepciones: se aplica poema a la obra extensa que recoge un sentido más bien épico y poesía cuando el sentido es de orden lírico y tiende hacia la brevedad". Esto es lo que sucede en El 
Poema de Mío Cid y esto es lo que sucede en las crónicas deportivas. Una crónica deportiva es un relato que posee dos elementos; la historia y el discurso. Lo que sucedió se puede decir de muchas formas discursivas: desde la noticia, el reportaje, la crónica, etc. Tomamos la crónica deportiva de fútbol porque permite introducir el punto de vista del autor, donde el cronista se erige en portavoz de la historia colectiva y se compromete en la enunciación y toma claramente partido por ese nosotros.

Pedro Salinas (1975: 37) cuando habla sobre El Poema de Mio Cid y un romance viejo, afirma que:

La primera actitud, y la más elemental del poeta ante la realidad, es creo el examinarla, tomar nota de ella, contarla. Esto es lo que hace que la épica, que observa la vida en movimiento, lo que pasó y nos da pura y simplemente el resultado de esa observación, aunque en la observación haya mucho personal.

El cronista deportivo también observa la realidad, da cuenta de ella e incluye un punto de vista personal sobre los acontecimientos. Relata una batalla, vislumbra a los héroes, describe los espacios en los que se desarrollan las lides y muestra los simbolismos de la derrota y la victoria y las tablas de una confrontación. Es una épica de los tiempos modernos.

El cronista deportivo de fútbol organiza el relato desde diferentes perspectivas temporales, espaciales y socio-simbólicas, acude tanto a la narración de los hechos como a la construcción poética de la vivencia de la realidad histórica.

La crónica procede etimológicamente del término latino "cronos". Cronos es el tiempo escrito en el pasado, inmediatamente pasado en relación con el acontecimiento, sin necesidad de seguir la linealidad temporal, introduciendo en el discurso un orden, una duración o una frecuencia por la que la historia es contada, contada de una manera que en gran forma indica o referencia una autoría, el autor de una crónica deja su huella. Se dirige a un público con un tema, con un acontecimiento, en un espacio diferente al propio receptor y a través de todas las mediaciones discursivas que hacen posible la comprensión del acontecimiento relatado.

El discurso de las crónicas de fútbol es, por tanto, un relato de una competición deportiva ocurrida en un periodo de tiempo y contada por un cronista que la ha vivido como testigo o como protagonista. Por tanto, el cronista al mismo tiempo que narra el evento desde el propio escenario de los hechos, toma partido y se coloca en la posición de testigo, protagonista, analista o intérprete de un relato que contiene unidades léxicas que forman a su vez espacios de significación más amplios (Marín, 2000).

\section{Metodología}

\subsection{Objetivos}

1. Investigar la presencia del léxico: bélico, jurídico, lúdico, mágico y social de las crónicas de fútbol en El Poema de Mio Cid. 
2. Comprobar la proporcionalidad de cada uno de estos léxicos descritos en la totalidad del discurso.

3. Analizar el discurso de las crónicas de fútbol teniendo presente los léxicos descritos.

4. Investigar las coincidencias léxicas que se repite en las distintas crónicas deportivas.

5. Relacionar las coincidencias léxicas de las crónicas que se repiten con $E l$ Poema de Mio Cid.

6. Investigar si el comportamiento de los léxicos en las crónicas deportivas de la derrota es similar al de la victoria.

7. Comprobar si el tamaño de una crónica se relaciona con el tema derrota o victoria.

\subsection{Hipótesis}

1. Los discursos de las crónicas deportivas actualizan a través de su léxico especializado el léxico del lenguaje épico y sus tipologías.

2. Existe una relación entre el tamaño de una crónica deportiva y la densidad de los distintos tipos de léxicos: bélico, jurídico, lúdico, mágico y social, de forma que a mayor tamaño de la crónica deportiva, mayor densidad de estos léxicos.

3. Cuando el léxico coincide en las diferentes crónicas deportivas del Campeonato Mundial de Fútbol, esa coincidencia también se da con el mismo léxico de El Poema de Mio Cid. Es decir, a mayor coincidencia del léxico en el corpus de las crónicas de los diarios seleccionados, mayor coincidencia entre este léxico y el de El Poema de Mío Cid.

4. El tamaño de las crónicas deportivas que narran la derrota es más corto y de menor densidad léxica que el de la victoria.

5. Los léxicos bélico, jurídico, lúdico, mágico y social, están presentes en todo el corpus analizado con distinto presencia y orden.

6. El léxico bélico muestra un mayor número de palabras diferentes que el resto de los léxicos (lúdico, mágico y social), y el jurídico, un menor número.

7. Existe una relación entre la presencia de cada léxico específico de las crónicas deportivas de fútbol y la presenca de ese mismo léxico en El Poema de Mío Cid.

\subsection{Técnicas metodológicas}

\subsubsection{Corpus de análisis}

Para el estudio de las unidades léxicas del lenguaje de las cronistas deportivas de fútbol hemos empleado las siguientes fuentes escritas (gráfico 1), tomando como criterio de selección los cinco primeros diarios por promedio de tirada, descartando los diarios gratuitos según el EGM del segundo trimestre de 2010, fecha en las que fueron escritas las crónicas deportivas, obteniendo como muestra de análisis la formada por los suguientes diarios: Marca, El País, As, El Mundo y El Periódico de Catalunya. 
Gráfico 1

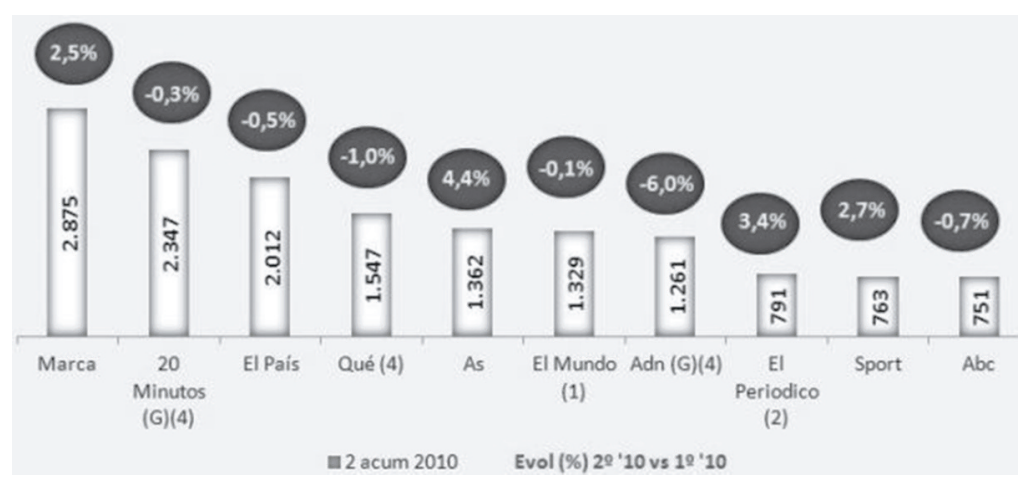

Fuente EGM $2^{\circ}$ acumulado 2010 - Ámbito España. Target Ind 14 años.

Se han analizado las siguientes crónicas deportivas:

1 Marca.com,16/06/10, España sufre un gravísimo accidente, crónica firmada por Roberto Palomar

2 Marca.com,11/07/2010, España gana su mundial en la final más dramática. Campeones del mundo de fútbol y de sufrimiento, crónica firmada por Roberto Palomar.

3 El País.com,16/06/2010, A España le puede la retórica crónica firmada por José Sámano.

4 El País.com,11/07/2010, Una España Mundial, crónica firmada por José Sámano.

5 As. Com, 16/06/2010, Toque de atención a España crónica firmada por de Óscar García.

6 As. Com, 11/07/2010, ;Campeones del Mundo! Gracias, crónica firmada por Iniesta de Óscar García.

7 El Mundo.es, 16/06/2010, España se lo pone crudo crónica firmada por Carlos E. Carbajosa.

8 El Mundo.es,13/07/2010, ¡Qué grande eres España! crónica firmada por Carlos E. Carbajosa.

9 El periodico.com,17/06/2010, España: alerta roja Suiza sorprende a la selección, que dominó de principio a fin sin remate, y le complica el Mundial, crónica firmada por Marcos López.

10 El periodico.com, 12/07/2010, España alcanza la gloria ante una mísera Holanda (1-0). La prórroga hizo justicia a un equipo que fue muy superior, crónica firmada por Carlos F. Marcote. 
Una vez elegidas las crónicas, establecimos los criterios para analizar los léxicos bélicos, jurídicos, lúdicos, mágicos y sociales. Se realizó un análisis del discurso para cada una de las crónicas y para cada uno de los léxicos, destacando aquel léxico que se repetía en todas o en alguna de las crónicas. Una vez realizada esta tarea para las crónicas de la derrota, se hizo lo mismo para las crónicas de la victoria y finalmente se reagruparon todos los léxicos señalados. Primero para todas las crónicas de la derrota y, después, se hizo lo mismo con los léxicos de las crónicas de la victoria, conformando el siguiente corpus de léxicos que fue contrastado, vocablo a vocablo, con el conjunto de léxicos de El Poema de Mio Cid. Posteriormente se señalaron los léxicos que se repetían en todas las crónicas deportivas y que aparecían también en El Poema de Mío Cid, siendo los resultados los que mostramos a continuación por término léxico y frecuencia de aparición en las diferentes crónicas.

\section{Análisis de los datos}

4.1. Análisis del léxico especializado de las crónicas deportivas

4.1.1. Análisis del léxico de las cinco crónicas deportivas de la derrota España ante Suiza

a) Léxico bélico seleccionado y frecuencia de aparición

\begin{tabular}{|l|l|l|l|l|l|}
\hline abatido 1 & abismo 1 & adversario 2 & alerta 2 & atravesar 1 & atropellado 1 \\
\hline azote 1 & bala 1 & caer 2 & calibre 1 & campeón 2 & campeona 1 \\
\hline campo 5 & capitán 1 & castillo 1 & cerrojo 1 & choque 1 & concluir 1 \\
\hline conquistar 1 & contra 1 & contrario 1 & cruel 1 & dañino 1 & débiles 2 \\
\hline defensivo 4 & derrota 9 & desplomaron 2 & diana 1 & disparar 1 & disparo 3 \\
\hline dominó 4 & duelo 2 & empuje 1 & encuentro 1 & estalló 1 & estrelló 1 \\
\hline final 2 & fogueo 2 & frente 4 & ganar 5 & golpetazo 1 & guardia 1 \\
\hline heroica 1 & impacto 2 & invadió 1 & invencible 1 & lanzó 1 & marcial 1 \\
\hline misil 1 & muerte 1 & muralla 1 & osado 1 & patadas 5 & patinazo 1 \\
\hline pegándose 1 & pelea 1 & peor 1 & perder 3 & recavido 1 & poder 5
\end{tabular}




\begin{tabular}{|l|l|l|l|l|l|}
\hline puntería 1 & punzante 1 & puñal 1 & rebelarse 1 & recámara 1 & refregar 2 \\
\hline rematar 7 & riesgo 1 & rival 3 & rupturas 2 & sangre 2 & sospechar 1 \\
\hline sufrió 1 & superioridad 1 & temió 1 & tensión 2 & trinchera 1 & triunfo 1 \\
\hline tropiezo 2 & velocidad 3 & víctima 1 & & & \\
\hline
\end{tabular}

b) Léxico jurídico seleccionado y frecuencia de aparición

\begin{tabular}{|l|ll|l|l|l|l|l|}
\hline abdicar 1 & apeló 1 & condena 1 & confesó 1 & desterrado 1 & excepción 1 & exilia 1 \\
\hline gobierno 1 & ley 1 & penitencia 1 & rango 1 & trono 1 & & \\
\hline
\end{tabular}

c) Léxico lúdico seleccionado y frecuencia de aparición

\begin{tabular}{|c|c|c|c|c|c|}
\hline aventura 2 & acierto 1 & comodín 1 & desconcertante 1 & desordenaba 1 & disciplina 1 \\
\hline disputado 1 & eje 1 & encuentro 1 & error 5 & imaginación 1 & imprevista 1 \\
\hline inteligencia 1 & jugar 11 & orden & organización 2 & partido 1 & plan \\
\hline sorprendió 1 & torneo 2 & & & & \\
\hline
\end{tabular}

d) Léxico mágico seleccionado y frecuencia de aparición

\begin{tabular}{|l|l|l|l|l|l|}
\hline accidente 2 & abismo 1 & afortunado 4 & azar 1 & creyendo 4 & desgracia 2 \\
\hline destino 1 & fatalismo 1 & fortuna 1 & ocasiones 1 & olimpo 1 & oportunidad 1 \\
\hline paraíso 1 & ruleta 1 & suerte 1 & & & \\
\cline { 1 - 3 } & & & & & \\
\end{tabular}


e) Léxico social seleccionado y frecuencia de aparición

\begin{tabular}{|l|l|l|l|l|l|}
\hline angustia 3 & afición 1 & amargamente 1 & ansioso 1 & atrofia 1 & coro 2 \\
\hline decepción 1 & deprimida 1 & desgracia 2 & dueño 4 & elogio 1 & emoción 1 \\
\hline equipo 4 & éxito 3 & frustrado 1 & gravísimo 1 & grupo 1 & inquietud 1 \\
\hline logro 1 & masajear 1 & recuperación 1 & remedio 1 & reproche 1 & socio 1 \\
\hline sufre 2 & vestuario 1 & & & & \\
\hline
\end{tabular}

4.1.2. Análisis del léxico de las crónicas de la derrota presentes en El Poema de Mio Cid

a) Léxico bélico seleccionado y frecuencia de aparición.

\begin{tabular}{|l|l|l|l|l|l|}
\hline abatio 1 & atravessaban 1 & cae 20 & campeador 184 & campo 44 & castillo 19 \\
\hline conquista 3 & contra 8 & daño 1 & derrota 3 & duelo 7 & encuentro 3 \\
\hline fin 4 & ganar 23 & golpes 1 & guardar 5 & vence 3 & lanzas 4 \\
\hline muerte 16 & osados 4 & peor 1 & perder 8 & poder 11 & puño 1 \\
\hline matar 14 & romper 1 & sangre 13 & sospechar 2 & temer 6 & \\
\hline
\end{tabular}

b) Léxico jurídico seleccionado y frecuencia de aparición: ninguna

c) Léxico lúdico seleccionado y frecuencia de aparición

\begin{tabular}{|l|l|l|}
\hline encuentro 3 & jugar 2 & orden 4 \\
\hline
\end{tabular}

d) Léxico mágico seleccionado y frecuencia de aparición

\begin{tabular}{|l|l|l|l|}
\hline esperanzas 1 & paraiso 2 & sorteabanles 1 & creerse 2 \\
\hline
\end{tabular}

e) Léxico social seleccionado y frecuencia de aparición

\begin{tabular}{|l|l|l|}
\hline dueños 3 & lograr 2 & sufrir 2 \\
\hline
\end{tabular}




\subsubsection{Análisis del léxico de las cinco crónicas deportivas de la victoria de España ante Holanda}

a) Léxico bélico seleccionado y frecuencia de aparición

\begin{tabular}{|c|c|c|c|c|c|c|}
\hline $\begin{array}{ll}\text { armó } & 1\end{array}$ & acción 3 & adversario 2 & afilaron 1 & agarrar 1 & agazapada 1 & agitó \\
\hline aguantar 2 & amagó 1 & amenazar 1 & anular 3 & apagar 1 & apretón 1 & arrasar 1 \\
\hline ataque 4 & temor 1 & atontó 1 & trinchera 1 & banda 4 & bandera 1 & burlando 1 \\
\hline cabeza 6 & $\begin{array}{ll}\text { caida } & 1\end{array}$ & campeón 13 & candado 1 & capitán 1 & castigo 1 & ceder 1 \\
\hline choque 2 & $\begin{array}{ll}\text { cima } & 1\end{array}$ & codazos 1 & conquista 1 & consumió1 & golpe 3 & controló 3 \\
\hline cuchillo 3 & débil 1 & defender 1 & defensa 8 & demoledor 1 & derribar 1 & desequilibrio 1 \\
\hline desterrada 1 & destrozó1 & dispara 1 & dolor 1 & dominio 2 & $\begin{array}{ll}\text { duelo } & 1\end{array}$ & $\begin{array}{ll}\text { dureza } 1 \\
\end{array}$ \\
\hline encaró 1 & ensuciaron 1 & epopeya 2 & erradicar 1 & esconder 2 & espiar 1 & estiró \\
\hline estopa 1 & expulsado 4 & fachada 1 & animal 2 & final & frontal 1 & frontera 2 \\
\hline fuego 2 & galopadas 1 & golpe 3 & gran 9 & grave 1 & gritar 2 & grosería 1 \\
\hline hazaña 1 & himno 1 & imperial1 & imponerse1 & incisivo 1 & inexperto 1 & inferiores 1 \\
\hline inhumano 1 & inseguridad 1 & lanzado 2 & latigazo 1 & limite 1 & malo & malgastó 1 \\
\hline mancharon 1 & mando 2 & mantequilla 2 & martillo 1 & martiriza 1 & matarife1 & méritos 2 \\
\hline meter 5 & miedo 2 & militancia 1 & mísera 2 & mordida1 & morir 1 & ocupa \\
\hline obligaron 1 & ocupación 1 & palo & patadas 8 & patriótico 1 & pegarle 1 & pelea \\
\hline peligro 2 & poder & presión 1 & problema 1 & pugilística 1 & punzadal & quemar 1 \\
\hline racanería 1 & ráfagas 1 & recibir 1 & relámpago 1 & rematar 4 & repartir 1 & replegó 1 \\
\hline romperles 1 & rozar & sacar 3 & $\begin{array}{ll}\text { salida } \quad 1\end{array}$ & salto & salvajes 2 & salvar \\
\hline S. Quintín 1 & sangre 2 & saña & seguridad 3 & sucio & sucumbió 1 & superior 1 \\
\hline tapar & terror 3 & tirar & tirar 7 & toque 2 & torturante 1 & trabajos 2 \\
\hline tregua & triunfo 3 & tumbó 1 & valiente 1 & vencedor 5 & veterano1 & vibrar \\
\hline violencia 3 & zampó 1 & zurdazo 2 & & & & \\
\hline
\end{tabular}




\section{Jurídico}

\begin{tabular}{|l|l|l|l|l|l|l|}
\hline alguacil 1 & amonestó 1 & antipedortivo 1 & arbitro 5 & condenada 1 & coronado 1 & deuda 1 \\
\hline dueños 1 & fichado 1 & infracción 2 & justicia 5 & juzgado 1 & permitió1 & poseer 1 \\
\hline rey 1 & saldar 1 & sancionada1 & verdugo 1 & víctima 1 & & \\
\hline
\end{tabular}

\section{Lúdico}

\begin{tabular}{|l|l|l|l|l|l|l|}
\hline acciones1 & aficionados 1 & alargue 1 & altemativas 1 & área 6 & arranque 1 & aventuras 1 \\
\hline balón 14 & camino 1 & campistas 1 & campo 6 & colocarse 1 & competir 3 & copa 2 \\
\hline cómer 2 & creación 2 & dibujaron 2 & disfrutar 2 & encender 1 & encuentro 4 & entrenador 1 \\
\hline error 3 & esfuerzos 1 & espectacular 1 & fallar 2 & falta 1 & fiesta 1 & fútbol 3 \\
\hline futbolista 1 & ganar 8 & gol 15 & juego 16 & jugador 2 & marcar 6 & ocasión 9 \\
\hline parada 1 & partido 14 & pase 10 & penalty 2 & perdido 1 & portería 4 & premio 1 \\
\hline profesión 1 & prórroga 12 & regates 1 & rival 4 & silbatos 2 & técnica 3 & tesón 1 \\
\hline vestuarios 1 & & & & & & \\
\hline
\end{tabular}

\section{Mágico}

\begin{tabular}{|l|l|l|l|l|l|l|}
\hline ángel 1 & bendición 1 & aventuranza 1 & bruja 1 & colosal 1 & corazón 1 & cumbre 2 \\
\hline destino 1 & divino 1 & elevó 1 & estrella 1 & etemidad 4 & fantasmas 1 & fidelidad 1 \\
\hline genio 4 & gloria 9 & Iluminado 1 & Ilusiones 1 & imaginó 1 & impereceder 1 & imposible 2 \\
\hline imprevisto 1 & mcomprensbbles 1 & infiemo 1 & inmortal 2 & inspiraron 1 & interminable 1 & leyenda 1 \\
\hline liturgia 1 & loco 1 & luces 1 & milagro 1 & misa 1 & oportunidad 1 & paraíso 2 \\
\hline pensar 1 & planeta 1 & prodigiosas 1 & sueños 3 & suerte 1 & utópica 1 & \\
\hline
\end{tabular}




\section{Social}

\begin{tabular}{|c|c|c|c|c|c|c|}
\hline abrumado 1 & acompaña 1 & agotada 1 & ahogado 1 & alegría 6 & amargado 1 & angustia 3 \\
\hline animó 1 & arropado 1 & asistido 1 & atormentar 1 & atrofia 1 & ausente 1 & ayudaron1 \\
\hline capaz & celebridad 1 & confianza 1 & congoja 1 & conjunto 4 & conocer 2 & consciente 1 \\
\hline convicción 1 & cuerdo 1 & decepción 1 & decisión 1 & deseo 1 & desgastado 1 & despiste 1 \\
\hline desquició 1 & digno 2 & discutir 2 & disfrutar 1 & dramático 1 & embriagador 1 & emotivo 1 \\
\hline entrega 1 & entusiasta 1 & equipo 12 & esconder1 & escuela 3 & estaba 1 & extraños 1 \\
\hline felicidad 2 & fenómeno 1 & frustración 2 & $\begin{array}{ll}\text { ganas } 1 \\
\end{array}$ & gente 1 & grupo 1 & héroe \\
\hline historia 6 & hito & hombre 6 & homenaje 1 & humildad 2 & Incapacitado 1 & comparecer 1 \\
\hline individuo 2 & inepto 1 & lamento 1 & libro & linaje & educado 1 & merecer 1 \\
\hline nervios 3 & olvido & oportuno 2 & padrinos 2 & pánico 1 & parece 2 & pasión \\
\hline penalidades 2 & persona 1 & prodigio 1 & propuesta 2 & protagonismo 1 & provocar 2 & pudor \\
\hline querer & razón & realidad 2 & repartir 1 & respetar 3 & selección 3 & sentir \\
\hline sucia & sufrir & suspiró 3 & tensión 1 & universal 4 & vergüenza 1 & vivir \\
\hline
\end{tabular}

\subsubsection{Análisis del léxico de las crónicas de la victoria coincidente con El Poema Mío Cid}

\section{Bélico}

\begin{tabular}{|l|l|l|l|l|l|l|}
\hline armas 45 & apretad 1 & ataca 1 & temen 2 & bando 7 & cabeza 10 & caer 4 \\
\hline campeador 184 & castigar 4 & retroceder 1 & codo 1 & conquista 2 & deportar 2 & dolor 3 \\
\hline duelo 7 & duro 5 & esconden 1 & fin 2 & frontera 3 & grande 158 & limita 1 \\
\hline mal 73 & desmanchar 2 & mando 8 & mártires 1 & matar 8 & mereçia 87 & meter 5 \\
\hline miedo 14 & morir 17 & preocupar 1 & obligados 1 & palo 2 & pelear 1 & poder 10 \\
\hline reçibo 40 & reparto 1 & saco 24 & salida 10 & salto 17 & salvo 12 & sangre 10 \\
\hline saña 1 & asegurándoles 1 & tirar 1 & valientes 2 & vencer 6 & & \\
\hline
\end{tabular}




\section{Jurídico}

\begin{tabular}{|l|l|l|l|l|l|}
\hline amonesta 1 & coronado 5 & adeudar 8 & dueños 46 & justicia 1 & Rey 260 \\
\hline
\end{tabular}

\section{Lúdico}

\begin{tabular}{|l|l|l|l|l|l|}
\hline acción 1 & arrancar 32 & campo 41 & coloca 1 & encuentro 1 & fallar \\
\hline ganar 101 & juego 5 & parado 5 & partid 1 & pasar 47 & perdido 3 \\
\hline portero 4 & premio 3 & vestidas 12 & & & \\
\hline
\end{tabular}

\section{Mágico}

\begin{tabular}{|l|l|l|l|l|}
\hline ángel 2 & bendiçiones 6 & corazón 1 & destino 1 & estrellas 1 \\
\hline gloriosa 5 & infiernos1 & misa 5 & paraiso 2 & sueño 3 \\
\hline
\end{tabular}

\section{Social}

\begin{tabular}{|l|l|l|l|l|l|l|}
\hline alegría 54 & ayudar 13 & confiar 1 & consintran 1 & decisión 1 & deseo 1 & entrega 1 \\
\hline entusiasmo 1 & esconden 1 & escuela 4 & estaban 12 & felicidad 1 & gente 28 & héroe 1 \\
\hline hombres 7 & lamentarse 1 & libro 1 & linaje 1 & olvidar 6 & padrino 1 & pareçen 3 \\
\hline personal 1 & quiero 36 & razón 32 & reparto 1 & selección 1 & sufrir 2 & suspiro 1 \\
\hline vergüenças 4 & vida 44 & reanima 1 & & & & \\
\hline
\end{tabular}

\subsection{Análisis comparativo de los léxicos}

\subsubsection{Análisis comparativo de los léxicos de las cinco crónicas de la derrota}

En el cuadro 1 recogemos los léxicos específicos de la derrota para cada uno de los periódicos y para cada uno de los léxicos: bélico, jurídico, lúdico, mágico y social, así como sus correspondientes totales en léxicos y en palabras para cada una de las crónicas deportivas. 
Cuadro 1. Léxicos específicos de la derrota

\begin{tabular}{|l|c|c|c|c|c|c|c|c|c|c|c|c|}
\hline VICTORIA & EL MARCA & EL PAÍS & & AS & & EL MUNDO & & PERIODICO & & TOTAL & \\
\hline & frecuencia & $\%$ & frecuencia & $\%$ & frecuencia & $\%$ & frecuencia & $\%$ & frecuencia & $\%$ & frecuencia & $\%$ \\
\hline TOTAL PALABRAS & 688 & 100,00 & 1203 & 100,00 & 1297 & 100,00 & 1094 & 100,00 & 698 & 100,00 & 4980 & 100,00 \\
\hline bélico & 31 & 4,51 & 42 & 3,49 & 82 & 6,32 & 67 & 6,12 & 62 & 8,88 & 284 & 5,70 \\
\hline juŕ́dico & 2 & 0,29 & 11 & 0,91 & 4 & 0,31 & 8 & 0,73 & 3 & 0,43 & 28 & 0,56 \\
\hline lúdico & 13 & 1,89 & 14 & 1,16 & 62 & 4,78 & 44 & 4,02 & 47 & 6,73 & 180 & 3,61 \\
\hline mágico & 2 & 0,29 & 20 & 1,66 & 21 & 1,62 & 10 & 0,91 & 7 & 1,00 & 60 & 1,20 \\
\hline social & 21 & 3,05 & 25 & 2,08 & 74 & 5,71 & 38 & 3,47 & 17 & 2,44 & 175 & 3,51 \\
\hline TOTAL LÉXICOS & 69 & 10,03 & 112 & 9,31 & 243 & 18,74 & 167 & 15,27 & 136 & 19,48 & 727 & 14,60 \\
\hline
\end{tabular}

Elaboración propia con datos de la investigación

Los datos del cuadro 1, referidos al análisis comparativo del léxico de la derrota indican una extensión diferente para cada una de las crónicas de los distintos periódicos; así el Marca con 586 palabras y El Mundo, con 652 palabras, están en la parte más baja del número de palabras de la muestra; El Periódico de Catalunya con 770 palabras, el As con 862 y El País con 919, son las crónicas más extensas. Se observa que existe una relación entre el número de palabras de una crónica de la derrota y su densidad de léxicos, de manera que un número alto de palabras conlleva un porcentaje alto de léxico. Así el Marca con 586 palabras tiene una densidad de léxicos específicos de 4,27\%, El Mundo con 652 palabras tiene un porcentaje de densidad de 5,22\%, El Periódico con 770 palabras tiene una densidad de 9,96\%, El País con 919 palabras tiene una densidad de 8,49\%. El único periódico que no sigue esta tendencia es el $A s$ que, con 862 palabras, tiene una densidad relativamente baja de $4,64 \%$.

El léxico bélico es el que mayor número de unidades posee con un $3,62 \%$, le sigue con un $1,40 \%$ el léxico social, con un $0,98 \%$ el léxico lúdico, con un $0,66 \%$ el mágico y, finalmente, el jurídico con un $0,32 \%$. El léxico bélico es el dominante en todas las crónicas periodísticas y los demás varían de una crónica a otra.

\subsubsection{Análisis comparativo de los léxicos de las cinco crónicas de la victoria}

En el cuadro 2 recogemos los léxicos de la victoria para cada uno de los periódicos y para cada uno de los léxicos: bélico, jurídico, lúdico, mágico y social, así como sus correspondientes totales en léxicos y en palabras para cada una de las crónicas deportivas.

Estos datos indican una extensión diferente para cada una de las crónicas deportivas; así el Marca que utiliza 688 palabras y El Periódico con 698 palabras, están en la parte baja de la muestra; mientras que El Mundo con 1094, El País con 1203, y el As con 1297 son las crónicas más extensas.

Se constata que no siempre existe una relación entre el número de palabras de una crónica y su densidad de léxicos específicos. Tienen relación el As, El Mundo y el Marca. El As con 1297 palabras tiene una densidad de léxicos de 18,74 \%, El Mundo con 1094 tiene un 15,27\%, el Marca con 688 tiene un 10,03\%. No tienen relación El País y El Periódico. El País, con un número alto de palabras 1203, tiene 
un porcentaje bajo de densidad de léxicos, 9,31 \% y El Periódico con un número bajo de palabras 698 , tiene un porcentaje alto de léxicos, $19,48 \%$.

Cuadro 2. Léxicos específicos de la victoria

\begin{tabular}{|c|c|c|c|c|c|c|c|c|c|c|}
\hline RELACION CRÓNICAS/CID DERROTA & \multicolumn{2}{|l|}{ BÉLICO } & \multicolumn{2}{|c|}{ JURÍDICO } & \multicolumn{2}{|c|}{ LÚDICO } & \multicolumn{2}{|c|}{ MÁGICO } & \multicolumn{2}{|c|}{ SOCIAL } \\
\hline Léxicos & frecuencias & $\%$ & frecuencias & $\%$ & frecuencias & $\%$ & frecuencias & $\%$ & frecuencias & $\%$ \\
\hline Se repiten en las crónicas & 14 & 17,07 & 0 & 0 & 6 & 30 & 3 & 20 & \begin{tabular}{|l|}
6 \\
\end{tabular} & 23,08 \\
\hline Coinciden en crónicas y Cid & 8 & 57,14 & 0 & 0 & 3 & 50 & 1 & 33,3 & 2 & 33,33 \\
\hline léxicos diferentes crónicas & 82 & 58,16 & 12 & 100 & 20 & 54,1 & 15 & 65,2 & 26 & 66,67 \\
\hline léxicos diferentes Cid & 30 & 13,10 & 0 & 0 & 4 & 33,3 & 3 & 60 & 3 & 42,86 \\
\hline Total palabras crónicas en léxicos & 141 & 54,86 & 12 & 4,67 & 37 & 14,4 & 23 & 8,95 & 39 & 15,18 \\
\hline Total palabras Cid en léxicos & 229 & 89,11 & 0 & 0 & 12 & 4,67 & 5 & 1,95 & 7 & 2,72 \\
\hline
\end{tabular}

Elaboración propia con datos de la investigación

El léxico bélico, en el total de todas las crónicas de la victoria, con un 5,70\%, es el que mayor porcentaje alcanza; le siguen el lúdico, con un 3,60\% y el social, con un 3,51\%. El léxico jurídico es el que menor porcentaje alcanza, con un $0,56 \%$ y le sigue el mágico con un $1,20 \%$. El léxico bélico es el más representado en todas las crónicas periodísticas y el jurídico el menos. Los demás léxicos, aunque se mantiene la tendencia general, varían dependiendo de cada una de las crónicas.

\subsubsection{Análisis comparativo de los léxicos de las diez crónicas}

La extensión de los léxicos en las crónicas de la victoria, con un 14,60\%, es superior a la extensión de los léxicos en las de la derrota, con un $6,78 \%$. Todas las crónicas de la victoria con 727 léxicos usan más del doble de voces que las de la derrota con 257 léxicos, mientras que las palabras de las crónicas de la victoria, con 4980, solo suponen una cuarta parte más que las de la derrota con 3789 palabras lo que significa que el léxico de la victoria es más denso que el de la derrota.

Sin embargo, el comportamiento de la densidad de léxicos con respecto al número de palabras en general y para cada periódico es diferente. En la victoria no existe una línea convergente entre el número total de palabras y el porcentaje de léxicos; así por ejemplo, el Marca tiene 688 palabras y un porcentaje de léxico específico de 10,03\% , mientras que El Periódico con un número de palabras equivalente, 698, alcanza un porcentaje de casi el doble, $19,48 \%$; sin embargo, el comportamiento de la derrota sigue una línea similar entre el número de palabras utilizado y los léxicos específicos para todos las crónicas deportivas. Exceptuamos el As que con una frecuencia de 828 palabras que sólo alcanza un léxico de 4,64\%.

En las crónicas de la victoria y de la derrota, el léxico bélico es el dominante y el jurídico el menor representado. El resto de los léxicos, con matizaciones, se comporta de una manera similar en la victoria y en la derrota; si bien cabe destacar que el léxico lúdico se impone en segundo lugar en la victoria mientras que en la derrota, es el social. El léxico mágico es el penúltimo en ambos casos. 
4.3. Análisis comparativo de los léxicos de las crónicas deportivas presentes en $E l$ Poema de Mío Cid

\subsubsection{Análisis comparativo de los léxicos de la derrota presentes en El Poema Mío Cid}

En el cuadro 3 recogemos los léxicos de la derrota que se repiten al menos en dos crónicas, también aquellos léxicos que coincidiendo en dos o más crónicas están presentes en El Poema de Mío Cid, y además se presentan los léxicos diferentes de las crónicas y de El Poema de Mío Cid y se hace un cálculo de los totales en el conjunto de las cinco crónicas y en El Poema de Mío Cid.

Cuadro 3. Léxicos comparativos de la derrota presentes en El Poema de Mío Cid

\begin{tabular}{|c|c|c|c|c|c|c|c|c|c|c|}
\hline RELACION CRÓNICAS/CID DERROTA & BÉLICO & & JURÍDIC & & LÚDICO & & MÁGICC & & $\mathrm{SOC}$ & \\
\hline Léxicos & frecuencias & $\%$ & frecuencias & $\%$ & frecuencias & $\%$ & frecuencias & $\%$ & frecuencias & $\%$ \\
\hline Se repiten en las crónicas & 14 & 17,07 & 0 & 0 & 6 & 30 & 3 & 20 & 6 & 23,08 \\
\hline Coinciden en crónicas y Cid & 8 & 57,14 & 0 & 0 & 3 & 50 & 1 & 33,3 & 2 & 33,33 \\
\hline léxicos diferentes crónicas & 82 & 58,16 & 12 & 100 & 20 & 54,1 & 15 & 65,2 & 26 & 66,67 \\
\hline léxicos diferentes Cid & 30 & 13,10 & 0 & 0 & 4 & 33,3 & 3 & 60 & 3 & 42,86 \\
\hline Total palabras crónicas en léxicos & 141 & 54,86 & 12 & 4,67 & 37 & 14,4 & 23 & 8,95 & 39 & 15,18 \\
\hline Total palabras Cid en léxicos & 229 & 89,11 & 0 & 0 & 12 & 4,67 & 5 & 1,95 & 7 & 2,72 \\
\hline
\end{tabular}

Elaboración propia con datos de la investigación

Cuando seleccionamos aquellas voces que se utilizan en dos o más crónicas, se observa que el léxico bélico con 14, es el que alcanza mayor grado de coincidencia, porque sus vocablos se repiten en más crónicas. Mientras que el lúdico y el social son similares entre sí, 6. El mágico es 3 y el jurídico 0; sin embargo, el comportamiento de la densidad difiere, así el porcentaje del lúdico es un 30\%, el del social un $23 \%$, el del mágico un $20 \%$ y por último, el del bélico un $17 \%$. Esto es debido a la mayor diversidad de léxicos en el lenguaje bélico (141) y la menor coincidencia de los mismos; mientras que en el resto de las léxicos, aunque la frecuencia es menor respecto al bélico; 12 para el jurídico, 37 para el lúdico, 23 para el mágico y 39 para el social, la coincidencia de las misma palabras en dos o más crónicas es superior, lo que hace que su porcentaje sea mayor.

El comportamiento es diferente según el tipo de léxico. Siendo el bélico el léxico que tiene una frecuencia absoluta mayor (141), mayor diversidad (82) y mayor frecuencia de repetición en dos o más crónicas (14), su porcentaje es menor en densidad (17,07\%) que el resto de los léxicos; lúdico $30 \%$, mágico $30 \%$ y social $23,8 \%$, porque el léxico bélico es más numeroso y diferente lo que hace que coincida menos entre las diferentes crónicas, mientras que el resto de los léxicos al ser menor en número y diferencia, cuando se utilizan, los cronistas tienden a utilizar los mismos.

El comportamiento de todos los léxicos de las crónicas deportivas de la derrota en El Poema de Mío Cid es diferente según el tipo de léxico; bélico, jurídico, lúdico, 
mágico y social. De nuevo el bélico es el léxico que tiene mayor frecuencia absoluta (229), mayor diversidad (30) y mayor frecuencia de coincidencia entre dos o más crónicas con El Poema (8) y su porcentaje es mayor en densidad (57,14\%) que el resto de los léxicos; jurídico (0), lúdico $(50 \%)$, mágico $(33,3 \%)$ y social $(33,3 \%)$ porque el léxico bélico coincidente en dos o más crónicas y presente en El Poema es más numeroso y diferente, lo que explica que, cuando los cronistas coinciden en utilizar un mismo léxico bélico, éste suele tener mayor presencia en El Poema de Mio Cid. Esta circunstancia se produce de igual manera en el resto de los léxicos, excepto en el jurídico porque no existe coincidencia alguna.

Sin embargo, si tomamos como partida los léxicos bélicos que no aparecen en más de una crónica, observamos que no tienen tanta presencia en El Poema de Mío Cid como cuando se utiliza por dos o más crónicas. Así cuando lo utilizan varios cronistas el porcentaje es de $57,14 \%$, mientras que cuando lo utiliza un solo cronista su porcentaje es de $13,10 \%$. Este comportamiento es similar para los léxicos lúdicos, (50\% frente al $33,3 \%)$ pero no así para el mágico $(33,3 \%$ frente a $60 \%)$ y social $(33,33 \%$ frente al $42,86 \%)$. Luego si un léxico no aparece en más de una crónica, tiene menor presencia en El Poema Mio Cid.

\subsubsection{Análisis comparativo de los léxicos de la victoria con El Poema Mio Cid}

En el cuadro 4 recogemos los léxicos de la victoria que se repiten al menos en dos crónicas; aquellos léxicos que, coincidiendo en dos o más crónicas, también están presentes en El Poema de Mio Cid; y además se presentan los léxicos diferentes tanto en las crónicas como en El Poema de Mío Cid y se hace un cálculo de los totales en el conjunto de las cinco crónicas y en El Poema de Mío Cid.

Cuadro 4. Léxicos comparativos de la victoria presentes en El Poema de Mío Cid

\begin{tabular}{|l|c|c|c|c|c|c|c|c|c|c|}
\hline RELACION CRÓNICAS/CID VICTORIA & \multicolumn{2}{|c|}{ BÉLICO } & \multicolumn{2}{|c|}{ JURÍDICO } & \multicolumn{2}{c|}{ LÚDICO } & \multicolumn{2}{c|}{ MÁGICO } & \multicolumn{2}{c|}{ SOCIAL } \\
\hline Léxicos & frecuencias & $\%$ & frecuencias & $\%$ & frecuencias & $\%$ & frecuencias & $\%$ & frecuencias & $\%$ \\
\hline Se repiten en las crónicas & 30 & 20,00 & 3 & 15 & 22 & 44 & 4 & 9,76 & 19 & 20,88 \\
\hline Coinciden en crónicas y Cid & 16 & 53,33 & - & 0 & 6 & 27,3 & 3 & 75 & 7 & 36,84 \\
\hline léxicos diferentes crónicas & 150 & 57,47 & 20 & 74,1 & 50 & 27,8 & 41 & 67,2 & 91 & 54,17 \\
\hline léxicos diferentes Cid & 40 & 10,70 & 4 & 6,78 & 12 & 6,42 & 9 & 34,6 & 17 & 6,80 \\
\hline Total palabras crónicas en léxicos & 261 & 35,90 & 27 & 3,71 & 180 & 24,8 & 61 & 8,39 & 168 & 23,11 \\
\hline Total palabras Cid en léxicos & 374 & 51,44 & 59 & 8,12 & 187 & 25,7 & 26 & 3,58 & 250 & 34,39 \\
\hline
\end{tabular}

Elaboración propia con datos de la investigación

La victoria toma otras formas de uso léxico diferentes con respecto a la derrota. Así, aunque la frecuencia del léxico bélico 30 es superior al resto de los léxicos específicos; jurídico 3, lúdico 22, mágico 4 y social 19; sin embargo, el porcentaje relativo se comporta de forma desigual; así el lúdico con un $44 \%$, el social con un $20,88 \%$, el bélico con un $20 \%$, el jurídico con un $15 \%$ y por último el mágico con un $9 \%$. Esto es debido a la mayor reiteración de lo lúdico porque, cuando se gana se tiende a la exaltación del discurso. Toda victoria debe ser compartida por eso se 
explica que el comportamiento de lo social $(20,88 \%)$ esté a la par que lo bélico $(20 \%)$ porque no existe una gran victoria que no conlleve una gran hazaña bélica.

El comportamiento es diferente según el tipo de léxico, siendo el bélico el que tiene una frecuencia absoluta mayor (261), mayor diversidad (150) y mayor frecuencia de repetición en crónicas (30); su porcentaje (20\%) está a la par en densidad con el léxico social (20,88\%), por debajo del lúdico (44\%) y por encima del mágico $(9,76 \%)$ y jurídico $(15 \%)$. El léxico bélico en la victoria es más numeroso y diverso, lo que favorece una menor coincidencia entre los cronistas.

La presencia en El Poema de Mío Cid de estos léxicos es diferente según cuál sea el tipo. De nuevo el bélico es el léxico que tiene mayor frecuencia absoluta (374), mayor diversidad (40) y mayor coincidencia entre crónicas y El Poema (16), pero su porcentaje no es el mayor en densidad $(53,33 \%)$ ya que le supera el mágico $(75 \%)$ debido a que la frecuencia es muy pequeña (4) y la coincidencia muy alta (3); el resto de los léxicos; jurídico (0), lúdico (27,3\%), y social $(36,84 \%)$ son inferiores.

El léxico bélico de las crónicas y presente en El Poema es más numeroso y diferente, lo que explica que cuando los cronistas coinciden en utilizar un mismo léxico bélico, éste tiene mayor presencia en El Poema de Mio Cid. Esta presencia se produce de igual manera en el resto de los léxicos, excepto en el lúdico debido a la alta frecuencia de repetición.

Sin embargo, si tomamos como partida el léxico bélico que no aparece en más de una crónica, observamos en el cuadro 4 que el léxico bélico no tiene tanta presencia en El Poema de Mío Cid como cuando se utiliza por dos o más crónicas. Así cuando se utiliza en varias crónicas el porcentaje es de 53,33\%, mientras que cuando sólo se utiliza en una se reduce al 10\%. Este comportamiento es similar para los léxicos lúdicos, $(27,3 \%$ frente al $6,42 \%)$, mágico $(75 \%$ frente a $34,6 \%)$ y social $(36,84 \%$ frente al $6,80 \%)$. Luego, si un léxico no aparece en más de una crónica, tiene menor presencia en El Poema de Mio Cid.

\section{Conclusiones}

El Poema de Mío Cid está presente en las crónicas deportivas de la derrota y de la victoria de España en el Campeonato Mundial de Fútbol de 2010. El lenguaje épico del poema se manifiesta a través del léxico bélico rico y diverso de todas las crónicas deportivas que se enriquece con el léxico lúdico que alcanza un mayor nivel de reiteración en las crónicas de la victoria. El resto de los léxicos, social, mágico y jurídico, al ser menor en número y diversidad, son menos utilizados por los cronistas y por tanto aparecen menos en El Poema de Mío Cid.

No existe una relación entre el tamaño de una crónica deportiva y la densidad de los distintos tipos de léxicos: bélico, jurídico, lúdico, mágico y social; por lo que la creatividad del periodista juega un papel determinante.

Cuando los periodistas utilizan el mismo léxico en sus crónicas deportivas, indistintamente de que relaten la derrota o la victoria, el porcentaje de aparición de esos términos en El Poema de Mio Cid es mayor que cuando se utilizan términos en los 
que no coinciden los cronistas. La pervivencia del vocabulario de El Poema de Mío Cid en las crónicas deportivas es más frecuente cuando ese vocabulario es coincidente en varias crónicas y es menor cuando éste no es compartido.

El tamaño de las crónicas deportivas de la derrota es más corto que el de la victoria y de menor densidad léxica porque la victoria en sí misma tiende a ser más expansiva y la frecuencia de léxicos lúdico, social y bélico son mayores, debido al sentido que tiene el juego y la capacidad de compartir en lo social expresado a través de las emociones, las identidades, etc., y porque una gran victoria no se puede explicar sin una gran hazaña.

Los diferentes léxicos están presentes en todo el corpus analizado con distinto peso y orden. Destaca el bélico tanto en frecuencia y diversidad en la victoria y en la derrota; le siguen a un distancia media lo lúdico y lo social, intercambiando posiciones según se trata de la victoria o de la derrota. En la derrota lo social y en la victoria lo lúdico. Lo mágico y lo jurídico son los léxicos menos utilizados y muy especialmente el jurídico que es el único que no estable relación alguna con $E l$ Poema Mí Cid porque en ninguno de los dos partidos de fútbol hubo jugadas muy problemáticas. Eso justifica la poca presencia del léxico jurídico en las crónicas por lo que se reduce la posibilidad de encontrarlo en El Poema Mio Cid.

\section{Bibliografía}

ALCOBA, A. (1984). Deporte y comunicación. Madrid: Dirección General de Deportes de la Comunidad Autónoma de Madrid. p. 147.

ALEIXANDRE-BENAVENT, R. (et al.) (2007). "Terminología y lenguaje deportivo en el fútbol”. En: Cultura Ciencia y Deporte, no 6, Vol. 2. Murcia. pp.117-123.

ANÓNIMO (1989) Cantar de Mio Cid . Madrid: Real Academia Española.

ARROYO ALMARAZ, I., GARCÍA GARCÍA, F. (2002). Didáctica aplicada a la lengua castellana y la literatura, Vol I. Madrid: Didáctica Hermes. Laberinto.

(2002). Lengua Castellana y Literatura con El deporte. Madrid: Ediciones del Laberinto.

BARRERO MUÑOZ, J. (2010). "El tratamiento de la violencia en el fútbol por la prensa deportiva". En: Doxa Comunicación, $\mathrm{n}^{\mathrm{0}}$ 5. Madrid. pp. 141-157.

BARTHES, R. (1957). "Le Tour de France comme épopée". En: Mythologies. Paris: Seuil. pp. 125-135.

BUSTOS TOVAR, F. (1992). "Épica y Crónica: Contraste en la estructuración del discurso". En: Actas del II Congreso Internacional de Historia de la Lengua espanola / coord. por Manuel Ariza Viguera, vol. 2, pp. 557-568.

CASTAÑÓN RODRÍGUEZ, J. (1993). El lenguaje periodístico del fútbol. Valladolid: Secretariado de Publicaciones de la Universidad, p. 202.

CATALÁN, D. (1963). "Crónicas Generales y cantares de gesta. El Mío Cid de Alfonso X y el del Pseudo Ben-Alfaray". En: Hispanic Review, XXXI, 3-4, pp. 196-215 y 291-306.

DYERS, N. (1980). "Crónica de Veinte Reyes. "Use of the Cid Epic: Perspectives, Method and Rationals". En: Romance Philology, XXXIII, 4, pp. 54-544. 
ÉLIAS, N (1994). Sport et civilisation: la violence maitrisée. Paris: Les amis du lexique français.

GALLEGO MORELL, A. (1959). "Un guardameta en la poesía española”. $A B C$ 22/02/1959.

GINER, S. (2003). Carisma y razón. La estructura moral de la sociedad moderna. Madrid: Alianza Editorial.

GIRÓN ALCONCHEL, J. L. (1989). "Las formas del discurso referido en el "Cantar de mio Cid". Madrid: Anejo XLIV del BRAE.

(1997). “Cohesión y oralidad: épica y crónicas”. En: Revista de poética medieval, no. 1, pp. 145-170.

HERNÁNDEZ MENDO, A. (1999). “Acerca del término Deporte”. En: Lecturas: EF y Deportes, año 4, no 17, pp.1-6.

HERRÁEZ PINDADO, A. J. (2004). "La metáfora en la formación del vocabulario del ciclismo en francés". En: Ibérica, 7, pp.107-123.

HERRERO GUTIÉRREZ, F. J. (2011). "España gana el Mundial 2010 de fútbol. El triunfo visto por la prensa española: aspectos deportivos y extradeportivos. En: Revista Comunicación y Hombre, 7, pp.159-171.

LABRADOR MÉNDEZ, G. (2007). "Cuando ataca Ronaldo ataca una manada. El discurso del fútbol en los media actuales como discurso épico (Estructuras, formas y funciones comparadas)". En: Culturas Populares. Revista Electrónica, 4, pp.1-50.

LISBONA, M., MEDINA, F., SÁNCHEZ, R. (2006). "Los orígenes de la Antropología del Deporte". En: Revista Pueblos y Fonteras Digital, no 2, pp.1-12.

LLOPIS GOIG, R. (2006) "El fútbol como ritual festivo. Un análisis referido a la Sociedad Española”. En: Anduli. Revista Andaluza de Ciencias Sociales, nº, 6, pp.115-132.

MAPELLI, G.(2004). "Locuciones del lenguaje del fútbol”. En: Centro Virtual Cervantes (consultado el 02/03/2012 en: http://cvc.cervantes.es/literatura/aispi/pdf/18/18_1 69.pdf)

MARIN MONTÍN, J.A. (2000). “La crónica deportiva: José A. Sánchez Araujo”. En: Ámbitos, $\mathrm{n}^{\mathrm{O}}$ 5, pp. 241-257.

MEDINA, J. M. (2011). "El lenguaje del fútbol, a ambos lados del campo o de la cancha". En: Tinkuy, 15, pp.127-133.

POWELL, B. (1983) Epic and the Chronicle: The "Poema de Mio Cid» and the "Crónica de Veinte Reyes». Londres: MHR.

REAL ACADEMIA ESPAÑOLA (1726-1739) (1990). Diccionario de Autoridades. Madrid: Gredos.

SALINAS, P. (1976). La realidad y el poeta. Madrid: Ariel.

SANTAMARÍA, M. (1995). "El léxico del fútbol en los periódicos". En: Estudios del mensaje periodístico, $\mathrm{n}^{\circ}$ 2, pp. 151-153.

TAMAYO FAJARDO, J.A. y ESQUIVEL RAMOS, R. (2005). “Aportaciones de la literatura a la enseñanza de la Historia del Deporte". En: Lecturas: EF y Deportes, año $10, n^{\circ} 83$, pp.1-7.

WHITE HAYES, M (2001). "Metaphor and Metonymy in thought and expression" En: G. Aguado \&P. Durán (eds.) (2001), La investigación en lenguas aplicadas: enfoque multidisciplinary. Madrid: Fundación Gómez-Pardo. pp. 47-64 


\section{Notas}

1 Agradecemos a Mercedes López Suárez, Catedrática de la Universidad Complutense de Madrid, su lectura atenta y sus aportaciones, sobre todo literarias que han enriquecido y fortalecido este trabajo.

2 Citado en Joaquín M. Marín Montín, J.A. (2000, p. 242) Marín Montín, J.A. (2000) "La crónica deportiva: José A. Sánchez Araujo". Ambitos, n 5, p. 242.

3 Romancero. Selección, introducción y notas de Manuel Alvar. (1988) Bruguera. Libro Clásico.

\section{Los autores}

Isidoro Arroyo Almaraz es doctor en Ciencias de la Información y Master en Técnicas de Comunicación en Servicios Sociales UCM-IMSERSO. Profesor Titular de Comunicación Audiovisual y Publicidad en la Universidad Rey Juan Carlos, y profesor visitante en diferentes universidades europeas e iberoamericanas. Investigador principal del proyecto del Ministerio de Ciencia e Innovación, "Desarrollo de un modelo de eficacia de la comunicación persuasiva del tercer sector en las redes sociales", así como de la Investigación sobre Fortalecimiento de los departamentos de comunicación de las ONG de Córdoba (Argentina).

Francisco García García es catedrático de Comunicación Audiovisual en la Universidad Complutense de Madrid. ExDirector del Centro Nacional de Información y Comunicación Educativa y exPresidente de la Asociación de la Televisión Educativa Iberoamericana. Premio Nacional de Investigación Educativa (MEC). Miembro de la Academia de las Ciencias y Artes de la Televisión. Director de diferentes Congresos Internacionales, como Internet en la educación y la educación en Internet, Sociedad Digital, y Ciudades Creativas (2001-2011). Editor de las revistas científicas Icono 14, Creatividad y Sociedad y Prisma Social. Director del grupo de investigación de UCM, SOCMEDIA, e IP de varios I+D como el de Sonactivos Digitales (2009-2011). 